Illinois State University

ISU ReD: Research and eData

Theses and Dissertations

$2-21-2020$

\title{
Mediation Among Childhood Sexual Abuse, Self-Objectification, and Risk Recognition
}

Michelle Maria Coventry

Illinois State University, mcoventry18@gmail.com

Follow this and additional works at: https://ir.library.illinoisstate.edu/etd

Part of the Clinical Psychology Commons

\section{Recommended Citation}

Coventry, Michelle Maria, "Mediation Among Childhood Sexual Abuse, Self-Objectification, and Risk Recognition" (2020). Theses and Dissertations. 1204.

https://ir.library.illinoisstate.edu/etd/1204

This Thesis is brought to you for free and open access by ISU ReD: Research and eData. It has been accepted for inclusion in Theses and Dissertations by an authorized administrator of ISU ReD: Research and eData. For more information, please contact ISUReD@ilstu.edu. 


\section{MEDIATION AMONG CHILDHOOD SEXUAL ABUSE, SELF-OBJECTIFICATION, AND RISK RECOGNITION}

\section{MICHELLE MARIA COVENTRY}

\section{Pages}

The purpose of the current study was to examine the relationship between childhood sexual abuse (CSA), self-objectification, and risk recognition in a sample of freshman, college women. Self-objectification was expected to interfere with the ability to readily identify risk (risk appraisal) and respond effectively (risk response), particularly for survivors of CSA. Participants were 335 freshman women ages 18 to 25 , with $47.8 \%$ reporting a history of CSA. Participants completed an online survey that assessed demographics, abuse history, and indicators of selfobjectification (body surveillance, body shame, and appearance anxiety). Participants also completed a task to assess risk recognition which included reading a sexually risky scenario ending in sexual assault. A series of correlations, $t$-tests, and mediation analyses were performed to examine the relationship between these variables. Self-objectification was found to significantly mediate the relationship between CSA and risk recognition, with specific aspects of self-objectification being related to specific aspects of risk recognition.

KEYWORDS: childhood sexual abuse; self-objectification; risk recognition; revictimization; freshman women 


\title{
MEDIATION AMONG CHILDHOOD SEXUAL ABUSE, SELF-OBJECTIFICATION, AND RISK RECOGNITION
}

\author{
MICHELLE MARIA COVENTRY
}

A Thesis Submitted in Partial Fulfillment of the Requirements for the Degree of

MASTER OF SCIENCE

Department of Psychology

ILLINOIS STATE UNIVERSITY 
(C) 2020 Michelle Maria Coventry 


\section{MEDIATION AMONG CHILDHOOD SEXUAL ABUSE, SELF-OBJECTIFICATION, AND RISK RECOGNITION}

MICHELLE MARIA COVENTRY

COMMITTEE MEMBERS:

Marla Reese-Weber, Chair

Jeffrey Kahn 


\section{ACKNOWLEDGMENTS}

I would like to acknowledge my committee chair, Dr. Marla Reese-Weber, for her time, support, and feedback throughout the thesis process. While working with Dr. Reese-Weber, I have grown tremendously as a writer and researcher. I would also like to acknowledge my committee member, Dr. Jeffrey Kahn, for providing additional feedback and guidance on statistical analyses. Finally, I would like to acknowledge my husband, Derek Coventry, for providing support, strength, and encouragement throughout the thesis process.

M. M. C. 


\section{CONTENTS}

Page

ACKNOWLEDGMENTS

TABLES

FIGURES $\quad$ v

$\begin{array}{ll}\text { CHAPTER I: STATEMENT OF THE PROBLEM } & 1\end{array}$

CHAPTER II: REVIEW OF THE LITERATURE 3

$\begin{array}{ll}\text { Childhood Sexual Abuse } & 3\end{array}$

$\begin{array}{lr}\text { Risk Recognition } & 6\end{array}$

$\begin{array}{ll}\text { Self-Objectification } & 12\end{array}$

$\begin{array}{ll}\text { Objectification Theory } & 12\end{array}$

$\begin{array}{ll}\text { Internalizing Outcomes of Self-Objectification } & 14\end{array}$

Childhood Sexual Abuse, Self-Objectification, and Risk Recognition 15

$\begin{array}{ll}\text { The Present Study } & 16\end{array}$

$\begin{array}{ll}\text { Hypotheses } & 17\end{array}$

$\begin{array}{ll}\text { CHAPTER III: METHOD } & 21\end{array}$

$\begin{array}{ll}\text { Participants } & 21\end{array}$

$\begin{array}{lr}\text { Measures } & 22\end{array}$

$\begin{array}{ll}\text { Demographic Questionnaire } & 22\end{array}$

Childhood and Adolescent Sexual Abuse $\quad 22$

$\begin{array}{ll}\text { Self-Objectification } & 23\end{array}$

$\begin{array}{ll}\text { Risk Recognition } & 25\end{array}$

$\begin{array}{ll}\text { Procedure } & 26\end{array}$ 
CHAPTER IV: RESULTS 29

$\begin{array}{ll}\text { CHAPTER V: DISCUSSION } & 37\end{array}$

$\begin{array}{ll}\text { Clinical Implications } & 40\end{array}$

Limitations and Future Directions 41

Strengths and Conclusion $\quad 43$

REFERENCES $\quad 44$

APPENDIX A: MASS EMAIL INFORMED CONSENT 50

APPENDIX B: SONA INFORMED CONSENT

APPENDIX C: DEBRIEFING STATEMENT 


\section{TABLES}

Table

Page

1. Frequency of Participants Reporting a History of Childhood Sexual Abuse

2. Correlations, Means, and Standard Deviations of Self-Objectification and Risk Recognition

3. Comparison of Women in the CSA and Non-CSA Groups 


\section{FIGURES}

Figure $\quad$ Page

1. Hypothesized Mediation Model 17

2. Mediation Model Connecting CSA and Risk Appraisal 33

3. Mediation Model Connecting CSA and Diplomatic Responses 34

4. Mediation Model Connecting CSA and Immobile Responses 35

5. Mediation Model Connecting CSA and Assertive Responses 36 


\section{CHAPTER I: STATEMENT OF THE PROBLEM}

Childhood sexual abuse (CSA) continues to affect children across the globe. According to a meta-analysis, including 65 international studies, $8 \%$ of men and $20 \%$ of women experience some form of CSA before the age of 18 (Pereda et al., 2009). Another study comparing college students in Singapore and the United States found women in the United States to have a higher prevalence of CSA and to report experiencing more severe forms of CSA than Singaporean women (Back et al., 2003). In the United States, Finkelhor et al. (2013) found the prevalence of CSA to be $27 \%$ for girls and $2 \%$ for boys. CSA has been linked to a substantial number of negative sexual, psychological, and interpersonal outcomes (Finkelhor \& Browne, 1985; Messman-Moore \& Long, 2003; Swanston et al., 2003). In particular, a history of CSA has been associated with later sexual revictimization (Messman-Moore \& Long, 2003).

One context in which sexual victimization is likely to occur is college. In a recent study, $22 \%$ of undergraduate students disclosed experiencing at least one incident of sexual assault (defined as sexualized touching, attempted penetration, or completed penetration) since starting college (Mellins et al., 2017). Compared to men, women were twice as likely to report experiencing college sexual assault, with freshman women at highest risk (Mellins et al., 2017). Among freshman women, research has consistently found those with a history of CSA to be most at risk, with CSA survivors being between 2 and 11 times more likely to experience sexual assault in adulthood than nonvictims (Mellins et al., 2017; Messman-Moore \& Long, 2003; Reese-Weber \& Smith, 2011).

Victimization in college has been explained by deficits in risk recognition. Risk recognition refers to the inability to perceive risk (risk appraisal) or respond to risk (risk response) in potentially dangerous situations (Messman-Moore \& Long, 2003). CSA survivors 
tend to miss signs of imminent danger and remain in risky situations longer than individuals without a history of victimization (Messman-Moore \& Brown, 2006; Messman-Moore \& Long, 2003).

In survivors of CSA, deficits in risk recognition have been explained by trauma-related symptoms, attachment anxiety, and personality-related constructs (e.g., assertiveness) (Bockers et al., 2014; Fortier et al., 2009; Franklin, 2013; Messman-Moore \& Brown, 2006; MessmanMoore \& Long, 2003; Sherrill et al., 2016; Soler-Baillo, Marx \& Sloan, 2005; Volkert et al., 2013). However, self-objectification has yet to be explored in relation to risk recognition. Therefore, the present study aimed to explore the relationship between CSA, self-objectification, and risk recognition in freshman women. 


\section{CHAPTER II: REVIEW OF THE LITERATURE}

\section{Childhood Sexual Abuse}

A clear conceptualization of the negative effects of CSA was first developed by Finkelhor and Browne (1985). According to their framework, the negative effects of CSA can be explained by one or more of the following traumagenic dynamics, or trauma-causing factors: traumatic sexualization, betrayal, stigmatization, and powerlessness (Finkelhor \& Browne, 1985). These factors negatively influence children's cognitive and emotional understanding of themselves and the world (Finkelhor \& Browne, 1985).

Traumatic sexualization is defined as the process in which a child's feelings and attitudes toward sexuality are misconstrued as a result of CSA. Traumatic sexualization occurs as a result of being rewarded with attention and gifts from an offender in return for sexual acts, when a specific anatomical part is given importance and meaning, and when negative memories of the abuse become associated with all sexual activity (Finkelhor \& Browne, 1985). In response to traumatic sexualization, survivors frequently develop inappropriate repertoires of sexual behavior and misunderstandings about their sexual self-concepts (Finkelhor \& Browne, 1985). Some individuals exhibit hypersexual behaviors as a result of traumatic sexualization, including sexual preoccupations and repetitive sexual behaviors (e.g., masturbation), displaying developmentally inappropriate sexual knowledge and interests, promiscuity, sexually aggressive behavior, and perpetration. On the other hand, some individuals develop an aversion to sex, sometimes resulting in sexual dysfunctions, such as difficulty reaching orgasm or vaginismus (Finkelhor \& Browne, 1985). Further, traumatic sexualization affects the mental clarity of CSA survivors. More specifically, memories of the abuse instill revulsion, fear, anger, and a sense of powerlessness (Finkelhor \& Browne, 1985). Survivors may also experience sexual guilt, sexual 
anxiety, and a fear of intimacy (Messman-Moore \& Long, 2003). These negative emotions often interfere with later sexual encounters (Finkelhor \& Browne, 1985). Not only do the negative emotions from abusive experiences transcend beyond the experiences themselves, but the questions, conflicts and learned behaviors do as well. Consequently, confusion about sexual norms and one's sexual identity often arise (Finkelhor \& Browne, 1985). Because survivors grow accustomed to the violent and controlling behavior of their abusers, they come to expect such violence and dominance later in intimate relationships and are consequently at greater risk for revictimization (Finkelhor \& Browne, 1985; Messman-Moore \& Long, 2003).

Betrayal, the second dynamic, occurs when children learn that someone whom they deeply trust has caused them harm (Finkelhor \& Browne, 1985). The effects of betrayal are comparable to those of grief. Feelings of betrayal can surface in response to an abuser or a family member who failed to protect or believe them. The betrayal dynamic is associated with depression, severe disenchantment and disillusionment, and attachment insecurity (Finkelhor \& Browne, 1985; Messman-Moore \& Long, 2003; Swanston et al., 2003). Attachment insecurity is manifested in different ways. Some individuals may develop an extreme dependency on romantic partners and exhibit impaired judgment about the trustworthiness of other people, whereas others isolate themselves from intimate relationships altogether. Those who exhibit overdependency and impaired judgment frequently find themselves in abusive relationships due to their inability to detect early signs of abuse (Finkelhor \& Browne, 1985).

Powerlessness, the third dynamic, is defined as the process in which a child's will, desires, and sense of efficacy are repeatedly violated (Finkelhor \& Browne, 1985). Powerlessness is reinforced when recurrent attempts to stop the abuse are unsuccessful. In response to powerlessness, children either experience a need for control, particularly male 
survivors, or intense fear and anxiety. Those who experience intense fear and anxiety suffer from nightmares, phobias, and hypervigilance (Finkelhor \& Browne, 1985). Because powerlessness impairs an individual's sense of efficacy and coping skills, despair, depression, and suicidality are other psychological outcomes that result from powerlessness (Finkelhor \& Browne, 1985; Messman-Moore \& Long, 2003; Swanston et al., 2003).

Stigmatization, the final dynamic, occurs when negative words used to describe the abuse (e.g., badness, shame, and guilt) are incorporated into a child's self-image. As these words become internalized, survivors view themselves as "spoiled merchandise" and often exhibit low self-esteem (Finkelhor \& Browne, 1985). Stigmatization comes from the abuser who blamed, humiliated, or conveyed shame to the victim or from family and community members who hold and express negative attitudes about the abuse (Finkelhor \& Browne, 1985). Because stigma surrounds the abuse, victims avoid talking about it, resulting in feelings of isolation (Finkelhor \& Browne, 1985). Extreme effects of stigmatization include self-destructive behavior and suicidality (Finkelhor \& Browne, 1985).

Sexual revictimization, which occurs when an individual with a history of CSA is victimized again in adulthood, is one of the most well-established outcomes of CSA (MessmanMoore \& Long, 2003). According to a recent meta-analytic review of 80 studies, the mean prevalence of sexual revictimization was 48\% (Walker et al., 2019). Not only are CSA survivors 2 to 3 times more likely to be victimized in adulthood than nonvictimized individuals, but those who are revictimized are also prone to more detrimental effects, such as higher levels of depression and anxiety, posttraumatic stress disorder (PTSD), dissociation, and substance use (Fortier et al., 2009; Walker et al., 2019). The high prevalence of revictimization has been 
explained by deficits in risk recognition. Therefore, the literature on risk recognition will be reviewed in the next section.

\section{Risk Recognition}

Risk recognition, defined as the ability to detect signs of imminent danger and react accordingly in a given situation, is measured through risk appraisal and risk response (Sherrill et al., 2016). Risk appraisal, the cogntive aspect of risk recognition, refers to the identification of a threat. Risk response, the behavioral aspect of risk recognition, refers to the behavioral response (voluntary or involuntary) provoked by threats of danger (Anderson et al., 2018). Although an individual may accurately appraise a situation as risky, they may or may not respond appropriately. Though risk recognition can be measured in multiple contexts, in the present study, risk recogntion was examined in the context of sexual assault.

While some studies have measured only risk appraisal or only risk response, most studies have included meaures of both risk appraisal and risk repsonse to assess risk recognition. To assess both constructs, historically, participants have been presented with one or more risk scenarios and asked a series of follow-up questions. Some scenarios are stopped at predetermined points to ask follow-up questions (Anderson et al., 2018; Messman-Moore \& Brown, 2006), whereas others wait for participants to intervene by pressing a computer key or buzzer (Marx \& Gross, 1995; Soler-Baillo et al., 2005; Volkert et al., 2013). In terms of scenario content, a date-rape interaction, involving a stranger, acquaintence, or both, is the most common type of risk scenario used. The medium of scenario presentation has also varied from study to study. Some risk scenarios have been presented as audio- or video-recordings, while others have been presented as written vignettes. 
One of the most widely used audiotaped risk scenarios was developed by Marx and Gross (1995). The recording illustrates two college students, a man and a woman, engaged in sexual activity. The scenario takes place in the man's apartment after the couple returns from a date at the movies. The audiotaped vignette progresses from brief kissing to completed sexual intercourse. Kissing is portrayed through sound, while physical contact (e.g., manual genital stimulation) is conveyed through conversation. At one point in the scenario, the woman resists sexual contact. She begins with gentle verbal requests and ends with assertive verbal responses (e.g., shouting). Prior to listening to the risk scenario, participants were informed about the dating history of the couple in the vignette, which varied by group condition.

One hundred male participants were randomly assigned to one of four group conditions. All groups were told the couple had engaged in sexual activity on their previous date. Two groups (token resistance conditions) were told the man attempted to make genital or breast contact, but the woman refused. However, when the man made a second attempt, the woman failed to refuse and let the man touch her. The other two groups (no resistance conditions) were told the man successfully touched the woman's genitals or breasts without any refusals. Marx and Gross (1995) found participants in the token resistance conditions to be more likely to listen to the date rape scenario longer (i.e., wait to indicate the man should stop) than participants in the no resistance conditions. These findings higlight the importance of persistent refusal (i.e., risk response) from the perspective of potential perpetrators.

The most widely used written risk scenario, the Risk Perception Survey (RPS), was developed by Messman-Moore and Brown (2006). The RPS was modeled after two vignettes described by Meadows et al. (1997). The RPS depicts two heterosexual interactions between a man and woman ending in date rape. One scenario involves an interaction with a stranger, while 
the other involves an interaction with an acquaintance. The interaction is presented as 25 numbered statements progressively increasing in risk. Clear and ambiguous risk factors previously identified in the literature by Norris et al. (1999) were incorporated into each vignette. Examples of ambiguous risk factors include alcohol consumption and degree of isolation from others, whereas clear risk factors include sexual comments, physical pressure while fondling, male persistence, and verbal persuasion. In the RPS, participants are asked to imagine themselves as the woman in the scenario.

The Risk Perception Survey was first used by Messman-Moore and Brown (2006) in a prospective study with a sample of college women. The relationship between risk recognition and sexual revictimization was examined. Data were collected at four different time points over the course of one academic year. Data were collected at the beginning of the fall semester (Time 1) and three follow-up sessions (Times 2 through 4) were conducted in 10-week intervals. Findings revealed that risk response was more strongly related to prospective rape and sexual victimization than risk appraisal. Moreover, responses to the acquaintance scenario were found to be more predictive of victimization than responses to the stranger scenario. Specifically, delayed responses in the acquaintance scenario were found to increase the risk of subsequent rape revictimization six-fold and double the risk of rape for those without a history of victimization. Lastly, women who agreed to accompany the acquaintance to a secluded place were most likely to report being raped during the follow-up period as compared to those who refused.

Risk appraisal has been measured in several different ways. Traditionally, risk appraisal has been measured by asking participants to press a computer key or buzzer when they feel the man in the scenario has "gone too far" or needs to refrain from making further sexual advances 
(Marx \& Gross, 1995; Soler-Baillo et al., 2005). Similarly, Volkert et al. (2013) asked participants to indicate when they felt the situation became too threatening. More recent studies have asked participants to indicate at which points they feel uncomfortable in the siutation (Franklin, 2013; Messman-Moore \& Brown, 2006). Studies using the computer key or buzzer method have measured risk appraisal using response latency (Marx \& Gross, 1995; Soler-Baillo et al., 2005). Response latency is defined as the length of time needed by participants to decide if the man in the scenario should stop making sexual advances because the woman is at risk (Marx \& Gross, 1995). Individuals who more quickly decide the man should stop (shorter latency) are considered to have high risk appraisal. Those who allow the scenario to continue (longer latency) are considered to have low risk appraisal. On the other hand, studies asking participants to indicate when they first felt uncomfortable convert participant responses into a "discomfort score" (Franklin, 2013; Messman-Moore \& Brown, 2006). A participant's "discomfort score" corresponds to the first statement number at which participants reported feeling uncomfortable. A low "discomfort score" suggests a participant was able to identify risk early in the scenario (high risk appraisal), whereas a high "discomfort score" suggests a participant was unable to identify risk until later in the scenario (low risk appraisal). Therefore, those with a longer latency score or a higher "discomfort score" are considered to have poor risk appraisal.

Soler-Baillo et al. (2005) found individuals with a history of victimization to exhibit longer response latencies (low risk appraisal) than nonvictims. In addition to measuring risk appraisal, Soler-Baillo et al. (2005) incorporated a physiological measure, heart rate activity (HR). As expected, nonvictims exhibited increased HR when risk assessment was critical, however, individuals with a history of victimization did not. A lack of increased heart rate 
suggests that those with a history of victimization did not appraise the situation as risky or fearful.

Like risk appraisal, risk response has been measured in several different ways. Franklin (2013) and Messman-Moore and Brown (2006) measured risk response by asking participants to indicate when they would leave the situation and calculated a "leave score." Much like participants' discomfort scores were calculated, a participant's "leave score" corresponds to the statement number at which they indicated wanting to leave the scenario. Individuals who indicate they would leave the situation earlier or have a lower "leave score" are considered to have high risk response. Those who report they would leave the situation later or have a higher "leave score" are considered to have low risk response.

Franklin (2013) included an additional measure related to risk response, delayed behavioral response. Delayed behavioral response is calculated by subtracting participants' discomfort score from their leave score. Difference scores denote a discrepancy between identifying feelings of discomfort (risk appraisal) and leaving the situation (risk response). Higher difference scores indicate the participant waited to leave the situation long after identifying feelings of discomfort. Franklin (2013) found individuals with a history of victimization to exhibit delayed behavioral response only when prior victimization involved intoxicated sexual assault. In addition, rape myth acceptance and pornography consumption were found to interefere with risk recognition ability. Specifically, high rape myth acceptance was related to low risk appraisal and risk response, but not with delayed behavioral response. In contrast, consumption of pornographic media was correlated with delayed behavioral response. Instead of restricting risk response to leaving a given scenario, Anderson et al. (2018) asked participants to indicate exactly how they would respond using the Behavioral Response 
Questionnaire (BRQ). The BRQ consists of 27 different hypothetical responses to threat, with each item being an assertive, diplomatic, or immobile response. Assertive items involve directly challenging or resisting a threat (e.g., hitting, kicking, scratching), whereas diplomatic items involve indirectly or gently challenging a threat (e.g., making an excuse). A diplomatic response is typically used when attempting to preserve a relationship. Immobile responses are provoked by extreme emotional distress and involve no response (e.g., freezing). In addition, Anderson et al. (2018) asked participants to report which five items they believed would best resolve or end the given situation and the order in which they would execute each behavior. However, only the first three items were analyzed. Finally, to understand the influence of age of victimization on risk response, participants were asked to report if they had experienced any sexual victimization, CSA, or developmental revictimization (in childhood and adolescence).

Overall, participants with a history of any sexual victimization had significantly higher diplomatic and immobile scores than women without a history of victimization (Anderson et al., 2018). With respect to sequence of behaviors, participants with a history of developmental revictimization were most likely to choose an immobile response as their second or third response choice. Similarly, participants with a history of CSA were most likely to choose an immobile response as their third choice. These results reveal women with a history of sexual victimization may eventually resort to immobile responses.

In summary, CSA is related to deficits in risk appraisal and risk response. Further, studies have found risk response to be more predictive of sexual revictimization than risk appraisal (Messman-Moore \& Brown, 2006; Messman-Moore \& Long, 2003). Previous research has found symptoms of PTSD, attachment anxiety, low self-efficacy, low sexual assertiveness, and maladaptive coping to explain the connection between CSA and poor risk recognition (Bockers 
et al., 2014; Fortier et al., 2009; Franklin, 2013; Messman-Moore \& Brown, 2006; MessmanMoore \& Long, 2003; Sherrill et al., 2016; Soler-Baillo, Marx \& Sloan, 2005; Volkert et al., 2013). One construct that has not been examined as a possible explanation for the connection between CSA and risk recognition is self-objectification. In the next section, I will review the literature on objectification theory and self-objectification.

\section{Self-Objectification}

\section{Objectification Theory}

To better understand consequences faced by women in a culture convoluted with sexually objectifying depictions of the female body, Fredrickson and Roberts (1997) proposed objectification theory. Objectification occurs when women are treated as instruments, mere bodies, designed for use and pleasure. According to Fredrickson and Roberts (1997), the objectification of women occurs in both obvious (e.g., sexual violence) and subtle (e.g., the male gaze) ways. The male gaze, colloquially termed "ogling," "leering," and "checking out," occurs when men visually inspect or stare at a woman's body (Gervais et al., 2013). The male gaze, though subtle, is arguably the most ubiquitous form of sexual evaluation (Fredrickson \& Roberts, 1997). The male gaze is enacted in three related contexts.

The first context in which female bodies are visually inspected is within interpersonal and social encounters. In general, women are gazed at more often than men and more likely to feel "looked at" in interpersonal interactions. Not only does the male gaze tend to be nonreciprocated, but it also tends to be accompanied by sexually evaluative commentary. The visual inspection of female bodies is not limited to real-life social interactions. The second context in which the male gaze appears is in interpersonal and social encounters depicted in visual media. In advertisements, women are frequently depicted staring off into the distance while men gaze upon 
them. The third context in which the male gaze appears is in visual media where bodies and body parts are spotlighted. In mainstream films, visual art, advertisements, television shows, music videos, magazines, and sports photography, the focus rests on the bodies of women. The exclusive focus on female bodies is in stark contrast to the portrayal of men in the media. For men, the focus tends to be on the head and face, with greater attention to facial detail. According to feminist scholars, the disproportionate focus on the female body in visual media is a clear act of objectification (Gervais et al., 2013).

Past research has found increased sexual objectification experiences to be associated with greater self-objectification (Franz et al., 2016). According to Fredrickson and Roberts (1997), the sexually objectifying treatment encountered by women often leads to a distorted perception of the physical self. More specifically, women come to view themselves from the perspective of the observer, as an object to be looked at and evaluated based on appearance. This phenomenon is termed self-objectification.

In the literature, self-objectification is defined as a state and a trait (Moradi \& Huang, 2008). State self-objectification refers to a heightened level of self-objectification triggered and manifested in certain situations, whereas trait self-objectification is considered to be a stable, individual difference (Fredrickson \& Roberts, 1998; Moradi \& Huang, 2008). In experimental studies, state self-objectification is typically induced by exposing participants to a sexually objectifying environment (Moradi \& Huang, 2008). Studies measuring trait self-objectification use self-report measures of self-objectification or body surveillance, the behavioral manifestation of self-objectification (Moradi \& Huang, 2008). Body surveillance is defined as persistent monitoring of physical appearance (Moradi \& Huang, 2008). A positive relationship between 
sexual objectification and body surveillance has been well-established (Gervais et al., 2011). The focus of the present study will be on trait self-objectification.

\section{Internalizing Outcomes of Self-Objectification}

The psychological and experiential consequences of body surveillance, more broadly sexual objectification, include shame and anxiety. The most common type of shame experienced by self-objectifying women is body shame. Body shame is the negative emotional response that occurs when women compare themselves to internalized or cultural standards (e.g., the thin ideal) and perceive themselves as falling short (Gervais et al., 2011; Moradi \& Huang, 2008). Experimental findings demonstrate heightened self-objectification promotes body shame in homogenous and racially/ethnically diverse samples of women (Moradi \& Huang, 2008). Body shame has also been found to mediate the relation of self-objectification or body surveillance with eating disorder and depressive symptoms (Moradi \& Huang, 2008). Similar to body shame, many self-objectifying women experience appearance anxiety (Fredrickson \& Roberts, 1997). Appearance anxiety results from not knowing when or how one will be looked at and evaluated (Fredrickson \& Roberts, 1997). Like body shame, heightened self-objectification has been found to increase appearance anxiety (Moradi \& Huang, 2008).

Although Fredrickson and Roberts (1997) described the direct experience of sexual abuse, assault or harassment as a form of objectification, very limited research has explored the relationship between various forms of sexual abuse, especially CSA, and self-objectification. Given self-objectification has been established as an outcome of repeated objectification, survivors of CSA would be more likely to self-objectify (Franz et al., 2016; Talmon \& Ginzburg, 2017). In the next section, I will provide theoretical and empirical support for the relationship between CSA, self-objectification, and risk recognition. 


\section{Childhood Sexual Abuse, Self-Objectification, and Risk Recognition}

When considering self-objectification in light of the theoretical framework proposed by Finkelhor and Browne (1985), self-objectification (body surveillance, body shame, and appearance anxiety) naturally falls under the stigmatization dynamic. Stigmatization occurs directly, when abusers blame or denigrate the victim, and indirectly, when pressured to maintain secrecy about the abuse (Finkelhor \& Browne, 1987). Most stigmatization results from negative attitudes maintained and moral judgments made by family and community members, making stigmatization difficult to escape (Finkelhor \& Browne, 1985; Finkelhor \& Browne, 1987). Consequently, many survivors internalize these negative messages, distorting their sense of value and worth (Finkelhor \& Browne, 1985). Therefore, self-objectification, which reflects a distorted perception of the physical self, would also be expected to be related to stigmatization following sexual abuse (Fredrickson \& Roberts, 1997).

Research has demonstrated a relationship between sexual abuse and self-objectification (body shame). Miles-McLean et al. (2014), who compared sexual trauma victims and nonvictims, found women reporting a history of sexual trauma experienced more selfobjectification (body shame) than nonvictims. Similarly, Watson et al., (2013), who examined CSA in relation to sexual risk-taking behaviors among a large, diverse sample of undergraduate women, found CSA to be directly related to self-objectification (body shame). Taken together, these studies indicate that a history of CSA may play a role in elevated levels of selfobjectification, particularly as a form of body shame.

To date, no research has explored self-objectification in relation to risk recognition. However, interruption to flow of consciousness, a proposed consequence of self-objectification, could explain this relationship. A person who is so consumed with thoughts about their own 
body is unlikely to attend to other aspects of their surroundings. In fact, research has found selfobjectification, experimentally manipulated by having participants wear a swimsuit or a sweater, to interfere with mental task performance (Fredrickson et al., 1998; Hebl et al., 2004). Further, Steer and Tiggemann (2008) found self-objectification, as measured by a general measure of self-objectification, body surveillance, body shame, and appearance anxiety to be significantly correlated with reported self-consciousness during sexual activity. These findings suggest women high in self-objectification continue to habitually monitor their bodies and experience body-related shame and anxiety in sexual contexts. Therefore, if self-objectification has the ability to disrupt attentional awareness and spill over into sexual encounters, then selfobjectification would presumably interfere with the ability to identify risk in sexually risky situations (risk appraisal).

With respect to risk response, self-objectification may also interfere with the ability to respond in risky situations. Franz et al. (2016), who sought to explain why a significant positive association between experiences of sexual objectification and sexual assault victimization exists, found higher body evaluation (a form of objectification) to predict sexual victimization via higher self-objectification (body surveillance) and lower sexual assertiveness. If selfobjectification undermines the ability to respond assertively in sexual situations, individuals who self-objectify would be most likely to elicit diplomatic and immobile responses in sexually risky situations. In summary, individuals who self-objectify, a probable outcome of stigmatization, are likely to miss signs of risk and respond inappropriately in sexually risky situations.

\section{The Present Study}

Extensive research has demonstrated a relationship between CSA, deficits in risk recognition, and sexual revictimization. Further, research has demonstrated a relationship 
between sexual abuse and body shame, and between body surveillance and low sexual assertiveness, sexual risk taking, and sexual victimization. Self-objectification, as indicated by body surveillance, appearance anxiety, and body shame, have all been found to carry over into sexual contexts. However, no research has explored self-objectification in relation to risk recognition. The purpose of the present study was to examine the direct relation of CSA to risk recognition (risk appraisal and risk response) and its indirect relation as mediated by body surveillance, body shame, and appearance anxiety, among a sample of freshman, undergraduate women (see Figure 1). These mediators may not have occurred at the same time but were treated as though for the purpose of this study.

\section{Figure 1}

\section{Hypothesized Mediation Model}

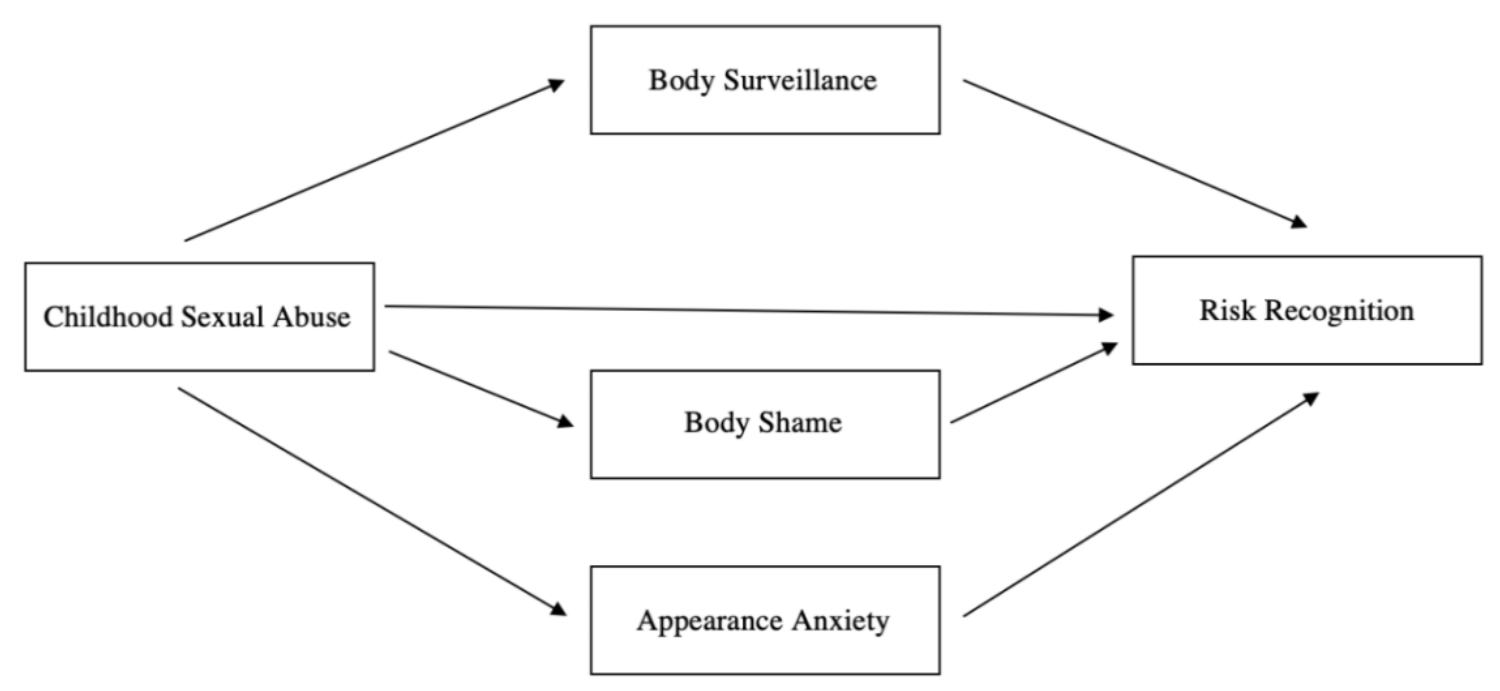

\section{Hypotheses}

As previously discussed, a relationship between a history of CSA and deficits in risk recognition has been established. More specifically, individuals with a history of CSA have been found to demonstrate longer response latencies compared to nonvictims, suggesting delays in 
recognizing risk (risk appraisal) (Gidycz et al., 2006; Soler-Baillo et al., 2005). Further, individuals with a history of CSA have been found to demonstrate delays in risk response (Franklin, 2013). They also tend to elicit diplomatic (i.e., indirectly or gently challenging a threat) and immobile responses (Anderson et al., 2018). Therefore, the present study tested the following hypotheses regarding the relationship between CSA and risk recognition:

H1: Women with a history of CSA will demonstrate deficits in risk recognition.

H1A: Women with a history of CSA will report lower average discomfort scores (low risk appraisal) across all nine segments of the risk recognition task than women without a history of CSA.

H1B: Women with a history of CSA will report higher average diplomatic and immobile scores and lower average assertiveness scores across all nine segments of the risk recognition task than women without a history of CSA.

Given the theoretically supported relationship between CSA (stigmatization) and selfobjectification, and the effects of self-objectification on attentional awareness and sexual assertiveness, I hypothesized that body surveillance, body shame, and appearance anxiety would mediate the relationship between CSA and risk recognition.

H2: Women with a history of CSA will report higher levels of self-objectification.

H2A: Women with a history of CSA will report higher body surveillance than women without a history of CSA.

H2B: Women with a history of CSA will report higher body shame than women without a history of CSA.

H2C: Women with a history of CSA will report higher appearance anxiety than women without a history of CSA. 
H3: Women reporting high levels of self-objectification will report low levels of risk appraisal. H3A: Body surveillance scores will be negatively correlated with average discomfort scores (risk appraisal).

H3B: Body shame scores will be negatively correlated with average discomfort scores (risk appraisal).

H3C: Appearance anxiety scores will be negatively correlated with average discomfort scores (risk appraisal).

H4: Women reporting high levels of self-objectification will report higher average diplomatic and immobile scores and lower average assertiveness scores than women reporting lower levels of self-objectification.

H4A: Body surveillance scores will be positively correlated with average diplomatic and immobile scores and negatively correlated with average assertiveness scores.

H4B: Body shame scores will be positively correlated with average diplomatic and immobile scores and negatively correlated with average assertiveness scores.

H4C: Appearance anxiety scores will be positively correlated with average diplomatic and immobile scores and negatively correlated with average assertiveness scores.

H5: The relationship between CSA and risk recognition will be mediated by body surveillance, body shame, and appearance anxiety.

H5A: The relationship between CSA and risk appraisal will be mediated by body surveillance, body shame, and appearance anxiety.

H5B: The relationship between CSA and diplomatic responses will be mediated by body surveillance, body shame, and appearance anxiety. 
H5C: The relationship between CSA and immobile responses will be mediated by body surveillance, body shame, and appearance anxiety. H5D: The relationship between CSA and assertive scores will be mediated by body surveillance, body shame, and appearance anxiety. 


\section{CHAPTER III: METHOD}

\section{Participants}

Participants were freshman, undergraduate women who were recruited through mass email and Illinois State University's Psychological Participant Pool, SONA. The mass email sample consisted of 257 participants, and the SONA sample consisted of 158 participants. Of these participants, 80 were deleted due to failing to complete the survey beyond the demographic questionnaire; identifying as a sophomore, junior, or senior; or being duplicated in both datasets. Therefore, the final sample consisted of 335 freshman women ranging in age from 18 to $25(M=$ 18.10, $S D=0.50)$. Participants identified as 77.3\% Caucasian; 6.6\% African American; $9.0 \%$ Hispanic/Latina, and $7.1 \%$ other. In terms of sexual orientation, participants identified as $79.7 \%$ heterosexual; $1.5 \%$ lesbian; $14.6 \%$ bisexual; $2.4 \%$ pansexual, and $1.2 \%$ other.

Of these participants, $160(47.8 \%)$ comprised the CSA group (see Table 1), and 175 (52.2\%) comprised the non-CSA group. Of participants who answered follow-up questions about the nature of the abuse, the majority reported being sexually abused between the ages of 15 and $18(n=52)$. The remaining participants reported being sexually abused between the ages of 4 and $14(n=27)$. In terms of perpetrators of the abuse, 63 participants reported the perpetrator was a friend or an otherwise known individual, whereas a small number of participants reported the perpetrator was a stranger $(n=4)$, family friend $(n=2)$, extended family member $(n=4)$, or immediate family member $(n=6)$. Thirty-four participants reported having one sexual encounter with their perpetrator, whereas 38 participants reported having multiple encounters. 


\section{Table 1}

Frequency of Participants Reporting a History of Childhood Sexual Abuse

\begin{tabular}{lcc}
\hline Hot Topics Item & $n$ & $\%$ \\
\hline $\begin{array}{l}\text { Someone has sexually touched me in ways that made me feel } \\
\text { uncomfortable. }\end{array}$ & 137 & $40.9 \%$ \\
$\begin{array}{l}\text { Before the age of 16, I had a sexual experience with an individual five or } \\
\text { more years older than myself (any sexual activity involving physical } \\
\text { contact). }\end{array}$ & 25 & $7.5 \%$ \\
$\begin{array}{l}\text { Another person has coerced me to engage in sexual activity (intercourse, } \\
\text { oral sex, anal sex, petting/fondling). }\end{array}$ & 103 & $30.7 \%$ \\
$\begin{array}{l}\text { I have engaged in sexual activity (intercourse, oral/anal sex, petting) when I } \\
\text { didn't want to because someone threatened to use physical force. }\end{array}$ & 36 & $10.7 \%$ \\
$\begin{array}{l}\text { I have been sexual assaulted. } \\
\text { Answering yes to any of the five questions above. }\end{array}$ & 76 & $22.7 \%$ \\
\hline
\end{tabular}

\section{Measures}

\section{Demographic Questionnaire}

Participants were asked to respond to a series of questions regarding gender, sexual orientation, age, ethnicity, living arrangement, relationship and socioeconomic status, family composition, and parental education.

\section{Childhood and Adolescent Sexual Abuse}

Childhood sexual abuse history was assessed using a shortened version of the Hot Topics Questionnaire (HTQ), a screening device created by Reese-Weber and Smith (2011). The shortened version is a 15-item questionnaire with 5 questions about mental health, 5 about substance abuse, and 5 about CSA. The questions related to CSA are: "1) Before the age of 18, someone has sexually touched me in ways that made me feel uncomfortable;" "2) Before the age of 16, I had a sexual experience with an individual five or more years older than myself (any sexual activity involving physical contact);" “3) Before the age of 18, another person has coerced 
me to engage in sexual activity (intercourse, oral sex, anal sex, petting/fondling);" "4) Before the age of 18, I had engaged in sexual activity (intercourse, oral/anal sex, petting) when I didn't want to because someone threatened to use physical force;" "5) I have been sexually assaulted before the age of 18." Participants were asked to answer dichotomously (yes or no). Participants who responded affirmatively to any of these 5 questions were placed into the CSA group and asked to complete a follow-up questionnaire. Participants who responded negatively to all 5 questions were placed into the non-CSA group.

Participants who responded affirmatively to any of the 5 aforementioned questions were asked to complete the Child Sexual Abuse Questionnaire (CSAQ; Finkelhor, 1979). The CSAQ is a 10 -item self-report measure querying about sexual experiences. Information gathered includes: age at time of abuse, age of perpetrator, relationship to perpetrator, nature of abuse, use of force, number of occurrences, duration of abuse, and disclosure of abuse.

\section{Self-Objectification}

The surveillance and body shame subscales of the Objectified Body Consciousness Scale were used to measure body surveillance and body shame (OBCS; McKinley \& Hyde, 1996). The surveillance subscale consists of 8 items designed to assess frequency of body monitoring and preoccupation with body appearance. Two sample items are: "I think more about how my body feels than how my body looks" [reverse scored] and "During the day I think about how I look many times." Participants were asked to respond on a 7-point scale ranging from 0 (strongly disagree) to 6 (strongly agree). Item values were averaged to equal a body surveillance score. Higher scores indicate more frequent body monitoring and thoughts about how the body looks, rather than how it feels. The body shame subscale consists of 8 items designed to assess the degree to which someone feels shame as a result of failing to meet cultural beauty standards. 
Two sample items are: "When I can't control my weight I feel like something must be wrong with me" and "I feel like I must be a bad person when I don't look as good as I could." Like the surveillance subscale, all items on the body shame subscale were averaged to equal a total body shame score. Higher scores reflect internalization of cultural body standards and negative beliefs held about the self due to unattained ideals. In a sample of undergraduate women, scores from both subscales demonstrated good internal consistency with alphas of .79 and .84 (McKinley \& Hyde, 1996). Scores on the body surveillance $(r=-.27)$ and body shame $(r=-.46)$ subscales were also found to be negatively correlated with body esteem, suggesting strong convergent validity (McKinley \& Hyde, 1996). In the present study, scores from the body surveillance and body shame subscales yielded good internal consistency with alphas of .82 and .88 , respectively. Appearance anxiety was measured using the Social Appearance Anxiety Scale (SAAS; Hart et al., 2008). The SAAS is a 16-item measure used to assess fears and worries about being evaluated based on overall appearance. On a Likert scale ranging from 1 (not at all) to 5 (extremely), participants were asked to indicate how characteristic statements such as, "I am afraid people find me unattractive" and "I worry people will judge the way I look negatively" were of them. For each participant, item values were averaged to equal a total social appearance anxiety score, with higher scores signifying higher levels of social appearance anxiety. In three samples of undergraduate students, scores from the SAAS demonstrated strong internal consistency $(\alpha=.94, .95$, and .94) (Hart et al., 2008). Using a subset of 100 participants from Sample 3, the SAAS scores also demonstrated good test-retest reliability $(r=.84)$ and good convergent validity with other measures of social anxiety, body image dissatisfaction, and related constructs (Hart et al., 2008). In the present study, the SAAS scores yielded excellent internal consistency $(\alpha=.97)$. 


\section{Risk Recognition}

The Risk Perception Survey (RPS), created by Messman-Moore and Brown (2006), asks participants to read a vignette depicting a man and a woman interacting in a social (party) setting. The interaction is normally presented as 25 numbered statements progressively increasing in risk, with the interaction ending in forced sexual intercourse. For the present study, the 25 statements were modified and divided into 9 segments. Three graduate students and one professor reviewed the scenario and decided where to make breaks. Previous research has used a stranger scenario and an acquaintance scenario. Because past research has found responses to the acquaintance scenario to be more predictive of prospective rape than responses to the stranger scenario (Messman-Moore \& Brown, 2006), the acquaintance scenario was used in the present study. To assess risk appraisal, participants were asked to imagine themselves as the woman in the scenario and asked, "How comfortable would you be?" after each segment. Participants were asked to respond on a Likert scale ranging from 0 (comfortable) to 4 (uncomfortable). Responses to each segment were averaged to create a discomfort score. A lower discomfort score indicates low risk appraisal, whereas a higher discomfort score indicates high risk appraisal.

To assess risk response, participants were asked to indicate how they would respond using a series of assertive, diplomatic, and immobile responses from the Behavioral Response Questionnaire (BRQ; Nurius et al., 2000). In addition to the original three subscales, we included an interested subscale, consisting of items meant to assess a more positive view of the situation and interest in pursuing the interaction. For the first five segments, participants were presented with 1 item from each subscale (interested, assertive, diplomatic, and immobile) and asked to indicate the likelihood of eliciting each response from 0 (not at all likely to be my response) to 4 (very much likely to be my response). Participants were presented with 3 items from the 
diplomatic, immobile, and assertive subscales for the remaining segments of the scenario. The items from each subscale were selected based on the items most frequently selected by participants in Anderson et al. (2018) and which made the most sense given the context of the scenario. In order for the items to coincide with the content of each segment, the items from each subscale were not the same across segments. The assertiveness items included: (1) "Tell him clearly and directly that I want him to stop" (2) "Tell him I like him, or that I find him attractive, but that I'm not ready for this" (3) "Push him away." The diplomatic items included: (1) "Jokingly tell him that he is coming on too strong" (2) "Nicely or apologetically tell him that I don't want to have sex" (3) "Tell him I had to leave." The immobile items included: (1) "Try to stiffen my body as a way of showing my lack of interest" (2) "I would be so overwhelmed that I feel almost paralyzed and would be unresponsive to what he is doing" (3) "I would struggle at first, but stop when I think it is hopeless" (4) "I would drink alcohol or take drugs (in the situation) as a way to calm myself down." The interested items included: (1) "Move closer to him to show that I am interested" (2) "Maintain eye contact to show I am interested" (3) "Tell him I like him or find him attractive." An average score for each subscale (interested, assertive, diplomatic, and immobile) was computed across segments.

\section{Procedure}

The present study was designed to be conducted in two phases, with Phase I being conducted at the beginning of the academic year (late August to early September) and Phase II being conducted at the end of the fall semester (late November to early December). However, due to a small number of participants, Phase II data were excluded from the present study. Participants completed an anonymous, online survey for both phases of the study on Qualtrics. 
Through Illinois State University's mass email system, all freshman women who opted to receive emails regarding research participation were invited to participate in the study. After clicking on the study link, participants were directed to the informed consent where requirements for participation (freshman women between the ages of 18 and 25), the nature of study, and opportunities for compensation (raffle for $\$ 25$ Amazon gift card) were described.

Participants were also able to participate on SONA, Illinois State University's Psychological Participant Pool. After signing up to participate, students were directed to a nearly identical survey as the mass email version. The only exception was the opportunity to receive extra credit rather than being entered into a raffle.

To ensure anonymity and match participant responses between Phase I and II, all participants were asked to create a unique self-identification code. Participants were asked to create a code based on the first two letters of their mother's maiden name, their middle initial, and the last four digits of their cell phone number.

Participants were then asked to complete the demographic questionnaire as well as the HTQ, CSAQ (follow-up to HTQ), OBCS, and SAAS. Participants were also asked to complete the risk recognition task, consisting of the RPS and BRQ. All measures, except the demographic questionnaire, were counterbalanced so that no participants ended with the risk recognition task or CSAQ. The purpose of such design was to minimize participant distress at the end of the study. Participants were evenly presented with two counterbalanced versions of the survey.

Given the potential for questions to trigger strong negative emotions about past sexual experiences, an "Exit Do Not Finish This Survey" button was located at the bottom left-hand corner of the screen to allow participants to exit at any time. The button directed participants to the debriefing statement, shown to all other participants upon completion of the survey, where 
contact information for PATH Crisis Center and Illinois State University's Student Counseling Center were provided.

In addition to the debriefing statement, participants were given the opportunity to provide supplemental consent to be contacted in the future for a second survey (Phase II) and to receive compensation. Those who elected to provide supplemental consent and receive compensation were redirected to a separate survey to maintain anonymity. In an attempt to pinpoint duplicate respondents, participants were asked if they already completed the survey via mass email or SONA and vice versa. Data matching the same identification code in both datasets were deleted, with responses with the later time of completion being deleted. 


\section{CHAPTER IV: RESULTS}

A series of preliminary correlations were computed to determine the relationships between the three indicators of self-objectification. All self-objectification variables (body surveillance, body shame, and appearance anxiety) were moderately correlated at the $p<.001$ level. Further, risk appraisal scores were significantly negatively correlated with interested scores, providing support for feelings of discomfort being a valid measure of risk appraisal. These correlations are shown in Table 1.

\section{Table 2}

Correlations, Means, and Standard Deviations of Self-Objectification and Risk Recognition

\begin{tabular}{lllllllll}
\hline Measure & 1 & 2 & 3 & 4 & 5 & 6 & 7 & 8 \\
\hline 1. Body Surveillance & -- & & & & & & & \\
2. Body Shame & $.53 * *$ & -- & & & & & & \\
3. Appearance Anxiety & $.58^{* *}$ & $.63^{* *}$ & -- & & & & & \\
4. Risk Appraisal & .04 & .02 & $.13 *$ & -- & & & & \\
5. Assertive & -.07 & $-.17 *$ & -.05 & $.16^{*}$ & -- & & & \\
6. Diplomatic & -.01 & -.06 & -.01 & -.12 & $.41 * *$ & -- & & \\
7. Immobile & $.31 * *$ & $.30 * *$ & $.29 * *$ & $.13 *$ & .09 & $.19 *$ & -- & \\
8. Interested & -.02 & -.03 & .04 & $-.28 * *$ & .05 & $-.12 *$ & .07 & -- \\
$M$ & & & & & & & & \\
SD & 5.16 & 3.99 & 2.95 & 2.93 & 2.75 & 3.20 & 2.75 & 1.91 \\
& 0.97 & 1.30 & 1.09 & 0.75 & 0.81 & 0.68 & 0.81 & 0.72 \\
\hline
\end{tabular}

Note. Higher risk appraisal scores indicate greater discomfort.

$* p<.05, * * p<.001$

The first hypothesis, stating women with a history of CSA would demonstrate deficits in risk recognition, was analyzed using four independent samples $t$-tests. These results are shown in Table 2. The results revealed women with a history of CSA did not report significantly lower 
risk appraisal than women without a history of CSA (Hypothesis 1A) nor did women with a history of CSA report significantly higher diplomatic and immobile scores or lower assertiveness scores than women without a history of CSA (Hypothesis 1B). Rather, women without a history of CSA reported significantly higher diplomatic scores than women with a history of CSA.

The second hypothesis, stating women with a history of CSA would report higher levels of self-objectification, was also analyzed with three independent samples $t$-tests. These results are also shown in Table 2. Hypothesis 2A, B, and C were all supported. More specifically, women with a history of CSA reported significantly higher body surveillance, body shame, and appearance anxiety than women without a history of CSA.

\section{Table 3}

Comparison of Women in the CSA and Non-CSA Groups

\begin{tabular}{|c|c|c|c|c|c|c|c|c|}
\hline & \multicolumn{6}{|c|}{ Abuse History } & \multirow[b]{3}{*}{$t$-value } & \multirow[b]{3}{*}{$d$} \\
\hline & \multicolumn{3}{|c|}{ CSA Group } & \multicolumn{3}{|c|}{$\begin{array}{l}\text { Non-CSA } \\
\text { Group }\end{array}$} & & \\
\hline & $M$ & $S D$ & $n$ & $M$ & $S D$ & $n$ & & \\
\hline Risk Appraisal & 2.89 & 0.75 & 159 & 2.98 & 0.75 & 166 & $t(323)=1.17, p=.244$ & 0.12 \\
\hline Diplomatic & 3.12 & 0.61 & 159 & 3.28 & 0.73 & 168 & $t(325)=-2.04, p=.017$ & -0.24 \\
\hline Immobile & 2.89 & 0.81 & 159 & 2.62 & 0.81 & 168 & $t(325)=3.03, p=.474$ & 0.33 \\
\hline Assertive & 3.28 & 0.60 & 159 & 3.38 & 0.70 & 168 & $t(325)=1.36, p=.173$ & 0.15 \\
\hline Body Surveillance & 5.30 & 0.93 & 154 & 5.03 & 1.00 & 162 & $t(314)=2.48, p=.014$ & 0.28 \\
\hline Body Shame & 4.27 & 1.25 & 154 & 3.73 & 1.30 & 162 & $t(314)=3.81, p<.001$ & 0.42 \\
\hline Appearance Anxiety & 3.14 & 1.08 & 158 & 2.76 & 1.07 & 163 & $t(319)=3.21, p=.001$ & 0.35 \\
\hline
\end{tabular}

Pearson product-moment correlation coefficients were computed to assess the relationship between body surveillance, body shame, appearance anxiety, and risk appraisal (Hypothesis 3). It was hypothesized that body surveillance, body shame, and appearance anxiety would be negatively correlated with risk appraisal. There was no significant correlation between body surveillance and risk appraisal or body shame and risk appraisal. However, appearance 
anxiety, though weak, was positively correlated with risk appraisal. Means, standard deviations, and correlations of these variables are shown in Table 1.

Pearson product-moment correlation coefficients were also computed to assess the relationship between indicators of self-objectification and assertive, diplomatic, and immobile scores (Hypothesis 4). It was hypothesized that body surveillance, body shame, and appearance anxiety would be positively correlated with diplomatic and immobile responses and negatively correlated with assertive responses. Hypothesis $4 \mathrm{~A}, \mathrm{~B}$, and C were partially supported. More specifically, body surveillance, body shame, and appearance anxiety were positively correlated with immobile scores but not diplomatic scores. Further, only body shame demonstrated a weak, negative correlation with assertive scores. Means, standard deviations, and correlations of these variables are shown in Table 1.

The fifth hypothesis, stating the relationship between CSA and risk recognition would be mediated by body surveillance, body shame, and appearance anxiety, was tested using a parallel multiple mediation analysis in PROCESS. Given that risk recognition is comprised of risk appraisal and risk response, the analysis was repeated four times to reflect risk appraisal as well as the three different types of risk response (diplomatic, immobile, and assertive) as outcome variables. In addition to examining direct effects, indirect effects, the pathways between CSA and risk recognition through the three indicators of self-objectification, were examined using bootstrapping.

Bootstrapping, a technique most relevant when examining sampling distributions, treats the study sample as a "population reservoir" from which several samples $(10,000$ in the current study) are drawn with continuous replacement (Mallinckrodt et al., 2006, p. 373). With continuous replacement, the probability of selecting cases remains consistent across draws, 
allowing for some members from the original sample to be excluded and others to be included multiple times in a given bootstrap sample (Mallinckrodt et al., 2006). The thousands of samples are used to determine a $95 \%$ confidence interval that addresses the asymmetric nature of the original sampling distribution, correcting for bias and enhancing statistical power (Mallinckrodt et al., 2006). If the confidence interval does not include zero then the indirect effect is statistically significant.

The first outcome examined was risk appraisal (see Figure 2). The pathways between CSA and body surveillance, $b=.26, t(302)=2.34, p=.02$, CSA and body shame, $b=.53, t(302)$ $=3.59, p<.001$, and CSA and appearance anxiety, $b=.38, t(302)=3.10, p=.002$, were significant. The pathways between body surveillance and risk appraisal, $b=-.01, t(299)=-.19, p$ $=.85$, and body shame and risk appraisal, $b=-.05, t(299)=-1.06, p=.29$, were not significant. However, the pathway between appearance anxiety and risk appraisal was significant, $b=.13$, $t(299)=2.48, p=.01$. The bootstrapped, unstandardized indirect effect of CSA on risk appraisal through body surveillance was -.003 , and the bootstrapped $95 \%$ confidence interval ranged from -.04 to .03. The bootstrapped, unstandardized indirect effect of CSA on risk appraisal through body shame was -.02 , and the bootstrapped $95 \%$ confidence interval ranged from -.08 to .02 . Therefore, there was no significant mediation of the relationship between CSA and risk appraisal through body surveillance or body shame. However, the bootstrapped, unstandardized indirect effect of CSA on risk appraisal through appearance anxiety was .05, and the bootstrapped $95 \%$ confidence interval ranged from .01 to .11 . Therefore, there was a significant mediation of the relationship between CSA and risk appraisal through appearance anxiety, indicating Hypothesis 5A was partially supported. It was expected that higher appearance anxiety would be related to 
poorer risk appraisal, however, the results indicated that higher appearance anxiety was related to better risk appraisal.

Figure 2

Mediation Model Connecting CSA and Risk Appraisal

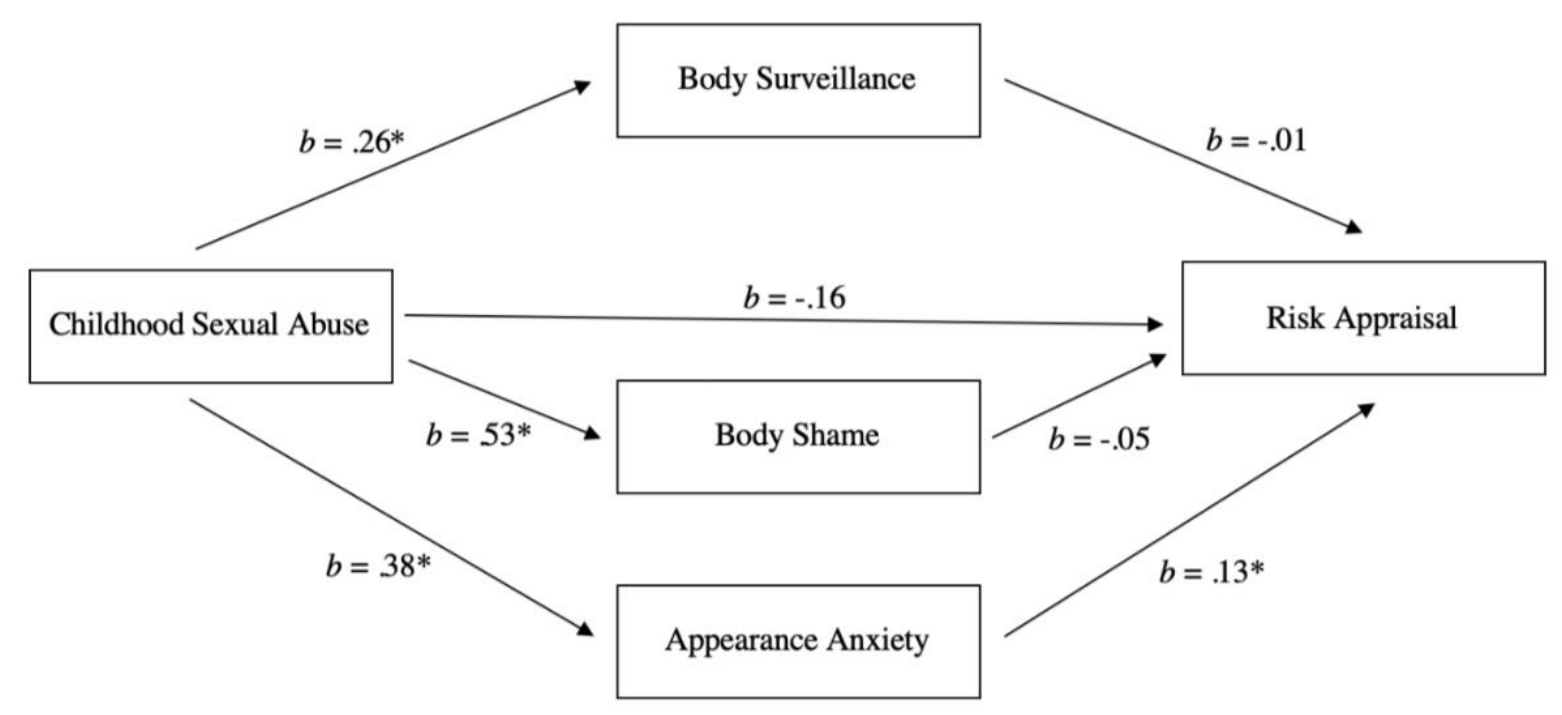

$* p<.05$

The second outcome examined was diplomatic responses (see Figure 3). Given that the left side of the model is the same across outcomes, despite minor differences due to missing data, the pathways between CSA and body surveillance, body shame, and appearance anxiety are only depicted in their corresponding figures for the remaining outcomes. The pathways between body surveillance and diplomatic responses, $b=.01, t(300)=0.21, p=.84$, body shame and diplomatic responses, $b=-.05, t(300)=-1.19, p=.24$, and appearance anxiety and diplomatic responses, $b=.04, t(300)=0.84, p=.40$ were not significant. The bootstrapped, unstandardized indirect effect of CSA on diplomatic responses through body surveillance was .003 , and the bootstrapped $95 \%$ confidence interval ranged from -.03 to .03 . The bootstrapped, unstandardized indirect effect of CSA on diplomatic responses through body shame was -.02, and the 
bootstrapped $95 \%$ confidence interval ranged from -.08 to .02. The bootstrapped, unstandardized indirect effect of CSA on diplomatic responses through appearance anxiety was .02, and the bootstrapped $95 \%$ confidence interval ranged from -.02 to .06 . Therefore, there was no significant mediation of the relationship between CSA and diplomatic responses through body surveillance, body shame, or appearance anxiety, indicating Hypothesis 5B was not supported.

\section{Figure 3}

Mediation Model Connecting CSA and Diplomatic Responses

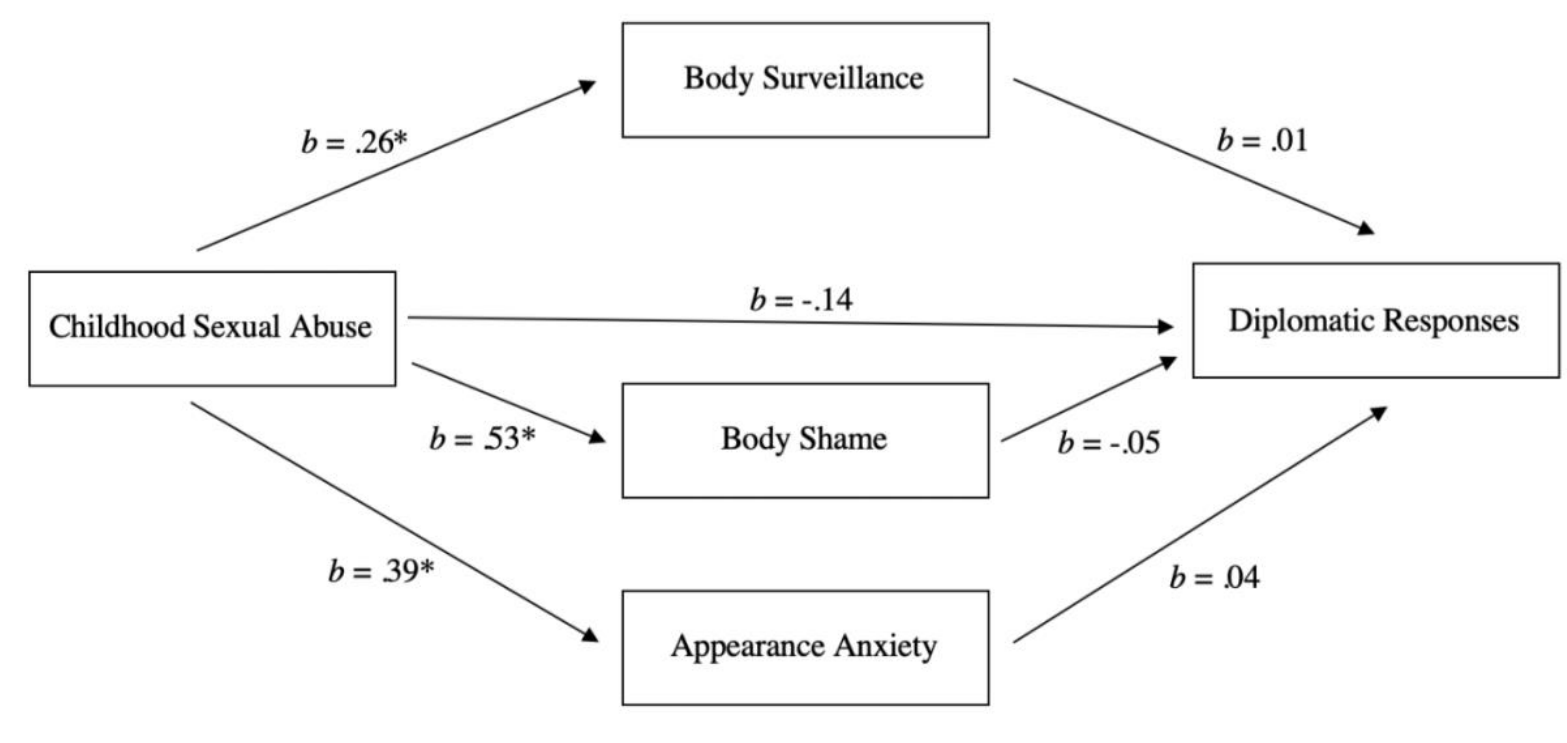

$* p<.05$

The third outcome examined was immobile responses (see Figure 4). The pathways between body shame and immobile responses, $b=.07, t(300)=1.57, p=.12$, and appearance anxiety and immobile responses, $b=.10, t(300)=1.90, p=.06$, were not significant. However, the pathway between body surveillance and immobile responses was significant, $b=.13, t(300)$ $=2.38, p=.02$. The bootstrapped, unstandardized indirect effect of CSA on immobile responses through body shame was .04, and the bootstrapped $95 \%$ confidence interval ranged from -.009 to .09. The bootstrapped, unstandardized indirect effect of CSA on immobile responses through 
appearance anxiety was .04 , and the bootstrapped $95 \%$ confidence interval ranged from -.001 to .10. Therefore, there was no significant mediation of the relationship between CSA and immobile responses through body shame or appearance anxiety. However, the bootstrapped, unstandardized indirect effect of CSA on immobile responses through body surveillance was .03, and the bootstrapped $95 \%$ confidence interval ranged from .003 to .08 . Therefore, there was significant mediation of the relationship between CSA and immobile responses through body surveillance. As expected, higher body surveillance was related to more immobile responses. Therefore, Hypothesis 5C was partially supported.

\section{Figure 4}

Mediation Model Connecting CSA and Immobile Responses

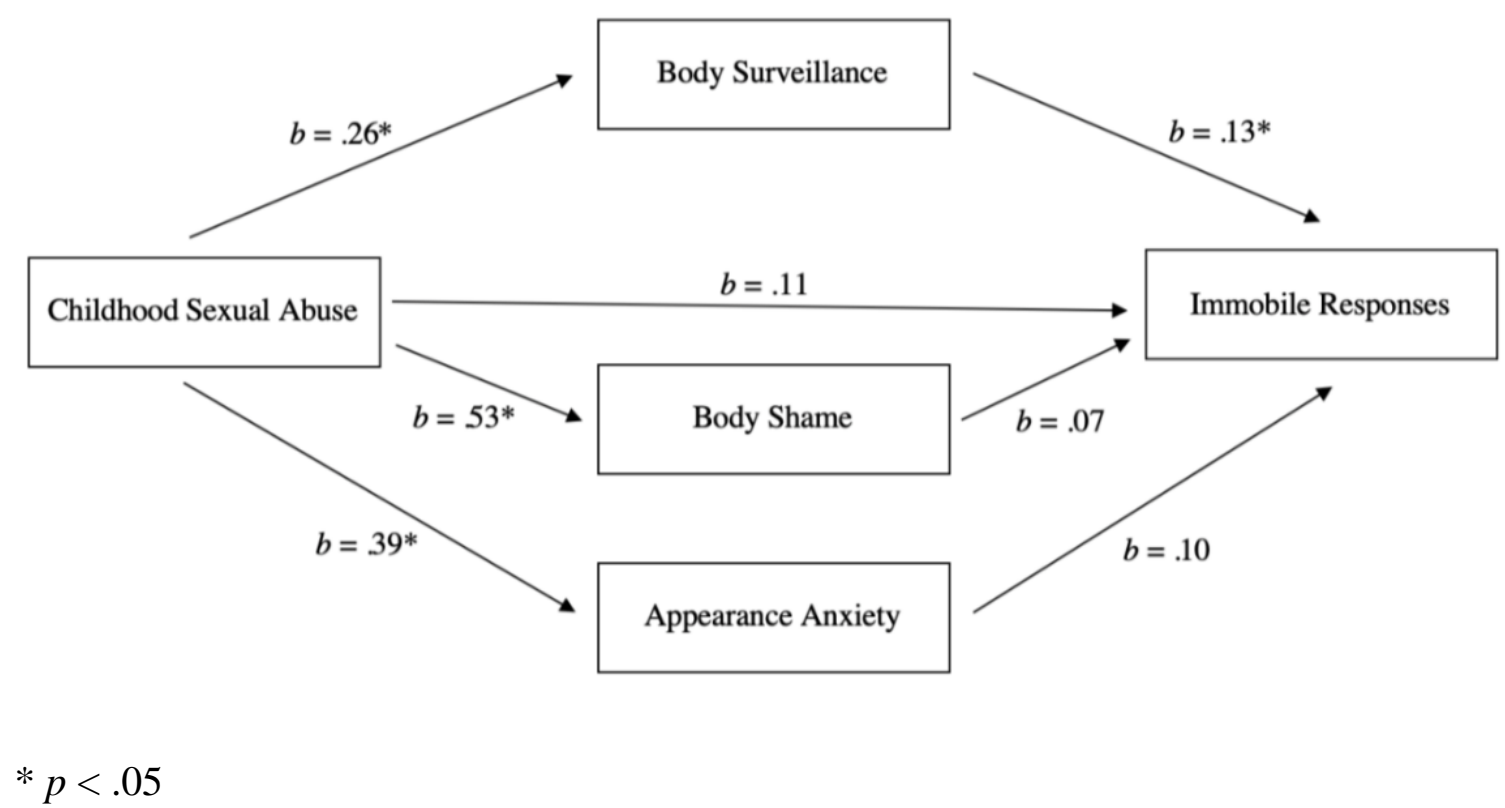

The fourth outcome examined was assertive responses (see Figure 5). The pathways between body surveillance and assertive responses, $b=-.02, t(300)=-.40, p=.69$, and appearance anxiety and assertive responses, $b=.06, t(300)=1.49, p=.14$, were not significant. However, the pathway between body shame and assertive responses was significant, $b=-.09$, 
$t(300)=-2.80, p=.005$. The bootstrapped, unstandardized indirect effect of CSA on assertive responses through body surveillance was -.005 , and the bootstrapped $95 \%$ confidence interval ranged from -.03 to .03 . The bootstrapped, unstandardized indirect effect of CSA on assertive responses through appearance anxiety was .02, and the bootstrapped $95 \%$ confidence interval ranged from -.006 to .06 . Therefore, there was no significant mediation of the relationship between CSA and assertive responses through body surveillance or appearance anxiety.

However, the bootstrapped, unstandardized indirect effect of CSA on assertive responses through body shame was -.05 , and the bootstrapped $95 \%$ confidence interval ranged from -10 to -.01 . Therefore, there was a significant mediation of the relationship between CSA and assertive responses through body shame. As expected, higher body shame was related to fewer assertive responses. However, the relationship between CSA and assertive responses remained significant, suggesting there was only partial mediation and another variable or variables may better explain the relationship between CSA and assertive responses.

\section{Figure 5}

Mediation Model Connecting CSA and Assertive Responses

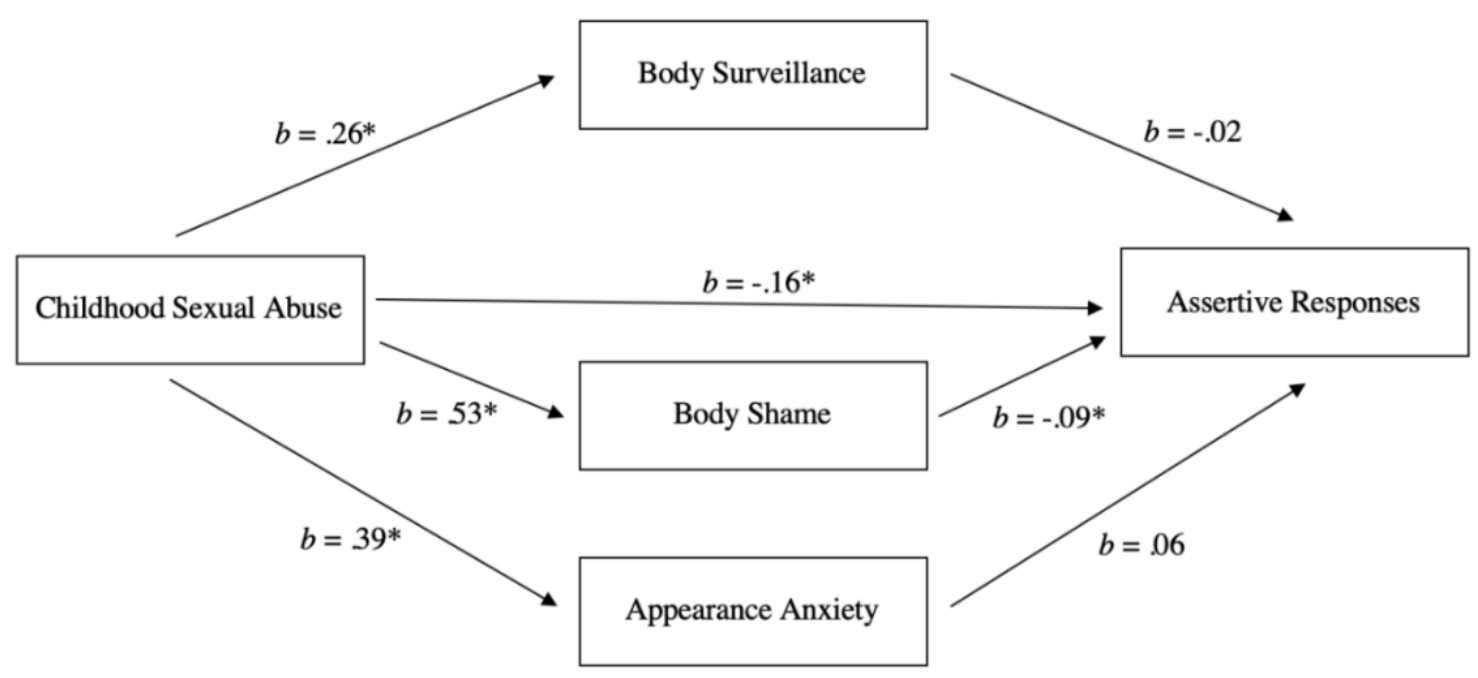

$* p<.05$ 


\section{CHAPTER V: DISCUSSION}

Previous research shows that $20-27 \%$ of women experience some form of sexual abuse before the age of 18, with prevalence rates increasing over time (Finkelhor et al., 2013; Pereda et al., 2009; Reese-Weber \& Smith, 2011). Using a broad definition of CSA, the present study found the prevalence rate to be $47.8 \%$. Minimal research has examined the relationship between CSA and self-objectification, particularly body surveillance and appearance anxiety, despite its strong theoretical basis and potential to interfere with risk recognition, a precursor to sexual revictimization (Messman-Moore \& Brown, 2006). Results of the present study indicated that women with a history of CSA demonstrate significantly higher levels of self-objectification (body surveillance, body shame, and appearance anxiety) than women without a history of CSA. Most notably, certain aspects of self-objectification mediated the relation between CSA and certain aspects of risk recognition.

There are two possible explanations for the alarmingly high rate of CSA in the present study. One possible explanation is the broad nature of the questions used to determine women with and without histories of CSA (e.g., "Before the age of 18, someone has sexually touched me in ways that made me feel uncomfortable") or the cutoff age for childhood victimization. While the present study utilized 18 as the cutoff age for childhood victimization, the cutoff age in other studies ranges from 13-17 years (Pereda et al., 2009). However, Pereda et al. (2009) did not find the broadness or narrowness of the definition or cutoff age to influence prevalence rates across 65 international studies. Another possible explanation is the \#MeToo movement, a social justice movement designed to raise awareness about sexual violence, particularly among women of color (Issitt, 2019). Perhaps the movement has diminished feelings of stigmatization (Finkelhor $\&$ Browne, 1985), giving women more courage to report their experiences of sexual abuse. 
Regardless of whether more women feel comfortable disclosing their abuse or more women are experiencing sexual abuse, the high prevalence rate reinforces the need for intervention.

As predicted, women with a history of CSA reported significantly higher levels of selfobjectification (body surveillance, body shame, and appearance anxiety) than women without a history of CSA. These results provide additional empirical support for the relationship between repeated sexual objectification experiences and self-objectification, a tenet of objectification theory (Fredrickson \& Roberts, 1997). While Watson et al. (2013) found CSA to be directly related to body shame, the current study is the first to establish a relationship between CSA and all three indicators of self-objectification (body surveillance, body shame, and appearance anxiety).

In the current study, I hypothesized that all three aspects of self-objectification would significantly mediate the relationship between CSA and risk recognition. However, the results indicated specific aspects of self-objectification were related to specific aspects of risk recognition. First, appearance anxiety was found to significantly mediate the relationship between CSA and risk appraisal. However, while it was hypothesized that higher appearance anxiety would predict poorer risk appraisal, higher appearance anxiety predicted better risk appraisal. Appearance anxiety, as opposed to body surveillance or body shame, was most likely found to mediate this relationship due to appearance anxiety being the cognitive aspect of selfobjectification and risk appraisal being the cognitive aspect of risk recognition. One possible explanation for the inverse relationship between appearance anxiety and risk appraisal could be the high convergent validity between appearance anxiety and social anxiety (Hart et al., 2008). Perhaps women high in appearance anxiety are more attuned to their surroundings, worrying about and attending to others' perceptions of them more so than their appearance. Therefore, 
some degree of anxiety proves to be beneficial in readily identifying risk. This finding is in line with the primitive function of anxiety, to signal danger.

Second, the reported tendency to habitually monitor the body (body surveillance) was found to significantly mediate the relationship between CSA and immobile responses, such that higher body surveillance predicted becoming immobile (i.e., drinking alcohol to calm oneself down or freezing) in a sexually risky scenario. These results make sense given body surveillance represents the behavioral manifestation of self-objectification (Moradi \& Huang, 2008). According to Fredrickson and Roberts (1997), body surveillance limits the flow of women's physical activities; attention is divided between the task at hand and bodily appearance. Consequently, women become hesitant in their movements. Therefore, women high in body surveillance would be expected to become immobile.

Finally, body shame, the emotional aspect of self-objectification, was found to contribute to one aspect of risk response-lower assertiveness. According to Fredrickson and Roberts (1997), the result of shame is a state of confusion with the inability to think, talk, or act. In the self-objectification literature, body shame has been associated with nonassertive sexual behaviors (Moradi \& Huang, 2008). Watson et al. (2013) described a disconnection from internal emotional states as a barrier to sexual self-efficacy (e.g., the ability to communicate refusal of unwanted sex). To cope with negative emotions, such as shame, Watson et al. (2013) argued that women lose awareness of current emotional states. Because of such disconnection, communication of thoughts and feelings becomes more difficult (Watson et al., 2013). Therefore, body shame, a negative emotional response, would be expected to interfere with the ability to communicate assertiveness (e.g., "Tell him clearly and directly that I want him to stop"). 
In direct opposition to findings from previous research (Anderson et al., 2018), women without a history of CSA were found to demonstrate significantly higher diplomatic responses than women with a history of CSA. Further, self-objectification was not found to mediate the relationship between CSA and diplomatic responses. These results could be explained by the significant, moderate correlation between diplomatic and assertive responses, suggesting diplomatic responses were similar to assertive responses and may not have represented a distinct category. Another possible explanation is adherence to rape myths. Perhaps nonvictims did not believe the scenario would result in rape and, therefore, waited until later in the scenario to endorse more assertive responses. This explanation is consistent with Franklin (2013) who found as rape myth acceptance increased, the later participants decided to leave a risky scenario.

\section{Clinical Implications}

These results can be used to inform the development of prevention and intervention programs designed to reduce sexual (re)victimization among college students, specifically freshman women with a prior history of sexual abuse. The lack of a significant correlation between immobile and assertive responses as well as the different predictors of such behaviors (i.e., body surveillance vs. body shame) suggests these responses are two distinct behavioral responses and prevention efforts should address both aspects of risk response. Therefore, while several sexual assault prevention programs include sexual assertiveness training, future prevention programs might consider focusing on multiple responses (i.e., assertiveness and overcoming immobility). In the short-term, clinicians should target risk appraisal and risk response. Once these have been addressed, clinicians can address self-objectification. 


\section{Limitations and Future Directions}

Despite promising results, the present study is not free of limitations. First, the sample consisted of predominantly white, college women. According to Moradi and Huang (2008), some research has found levels of body surveillance to differ among women born in the United States and women who immigrated to the United States at a later age. Some research has also found body surveillance to be higher in European American women as compared to African American and Latina women (Moradi \& Huang, 2008). Therefore, a more diverse sample could potentially reveal differences in body surveillance as well as body shame and appearance anxiety. More importantly, given the previous findings in mean score differences among ethnic groups, the relationships among self-objectification, risk appraisal, and risk response may also vary by ethnic group. Future research should attempt to include a more diverse sample and compare women of different ethnic groups.

Second, responses to the risk recognition task might not be an accurate representation of how one might respond in real life due to difficulty imagining oneself as the woman in the scenario. To help participants imagine themselves as the woman in the scenario, virtual reality, a validated procedure for assessing risk response, could be used (Jouriles et al., 2011). However, the use of virtual reality increases the likelihood of triggering strong negative emotions about past sexual experiences and needs to be used with caution. Including research assistants who are highly trained to manage strong negative reactions is an example of one precaution that could be taken.

Third, participants were not compared based on frequency or age of CSA, which have been found to affect risk recognition in different ways. For example, women with a history of one victimization experience have been found to demonstrate better risk recognition than women 
with a history of repeated victimization experiences (Messman-Moore \& Long, 2003).

According to Messman-Moore and Long (2003), perhaps women with a history of one assault are more sensitized to danger cues than repeatedly victimized women who have become desensitized. Moreover, Anderson et al. (2018) found participants to differ in diplomatic and immobile scores depending on whether sexual victimization occurred before or after the age of 14. Therefore, future research should take previous abuse frequency and age of abuse into account.

Fourth, computing mean discomfort, assertive, diplomatic, and immobile scores did not capture the exact moment risk was recognized or specific behaviors would have been performed. Given that the scenarios were created to gradually increase in risk, participants would be expected to have become more uncomfortable and assertive as the scenario progresses. Therefore, moments indicative of deficits in risk recognition might have been missed. Future research should explore fluctuations in risk appraisal and risk response by identifying trajectories of risk recognition over the time course of the scenario.

Fifth, mediation was tested with cross-sectional data. Given that mediation unfolds over time (i.e., time must pass before the independent variable can have an effect on the dependent variable), the use of cross-sectional data is problematic (Maxwell \& Cole, 2007). Specifically, cross-sectional data often results in biased estimates of longitudinal parameters (Maxwell \& Cole, 2007). In other words, cross-sectional direct and indirect effects are often different from longitudinal direct and indirect effects. Therefore, these mediational findings must be interpreted with caution. Future research might attempt to collect data at multiple time points.

A final limitation was the inability to obtain a sufficient number of participants for the second phase of the study, preventing a relationship between risk recognition, self- 
objectification, and sexual revictimization from being explored. Future research might include more incentives for participation in multiple phases.

\section{Strengths and Conclusion}

One strength of the present study is the inclusion of risk appraisal and risk response in the form of specific behavioral responses. In other words, instead of limiting risk response to whether or not participants would leave the scenario, participants were asked how they would respond to the situation (e.g., assertive, diplomatic, immobile). The inclusion of multiple response options is important given that several studies have found risk response to be more predictive of revictimization than risk appraisal (Messman-Moore \& Brown, 2006). A second strength is data being collected from a specific subsample of college students, freshman women. Obtaining data from freshman women is pertinent given the increased risk of sexual (re)victimization during the first year of college (Reese-Weber \& Smith, 2011). A third strength is the simultaneous examination of the three indicators of self-objectification. Examining all three indicators at the same time in relation to risk recognition revealed which aspects of selfobjection most strongly interfered with specific aspects of risk recognition.

Results from the current study revealed that women who experience sexual abuse before the age of 18 are more likely to self-objectify than their nonabused peers. Each indicator of selfobjectification was found to influence risk recognition. Specifically, appearance anxiety was related to risk identification, body surveillance was related to inhibited risk responses, and body shame was related to limited assertiveness in a sexually risky situation. 


\section{REFERENCES}

Anderson, R. E., Cahill, S. P., \& Delahanty, D. L. (2018). Differences in the type and sequence order of self-defense behaviors during a high-risk victimization scenario: Impact of prior sexual victimization. Psychology of Violence, 8, 339-348.

https://doi.org/10.1037/vio0000169

Back, S. E., Jackson, J. L., Fitzgerald, M., Shaffer, A., Salstrom, S., \& Osman, M. M. (2003). Child sexual and physical abuse among college students in Singapore and the United States. Child Abuse \& Neglect, 27, 1259-1275. https://doi.org/10.1016/j.chiabu.2003.06.001

Bockers, E., Roepke, S., Michael, L., Renneberg, B., \& Knaevelsrud, C. (2014). Risk recognition, attachment anxiety, self-efficacy, and state dissociation predict revictimization. PLoS ONE, 9(9), e108206. https://doi.org/10.1371/journal.pone.0108206

De Waal, M. M., Christ, C., Messman-Moore, T. L., \& Dekker, J. J. M. (2019). Changes in risk perception after sexual victimization: Are we following the right track? Journal of Interpersonal Violence. https://doi.org/10.1177/0886260519848790

Finkelhor, D. (1979). Sexually victimized children. Free Press.

Finkelhor, D., \& Browne, A. (1985). The traumatic impact of child sexual abuse: A conceptualization. American Journal of Orthopsychiatry, 55, 530-541. https://doi.org/10.1111/j.1939-0025.1985.tb02703.x

Finkelhor, D. (1987). The trauma of child sexual abuse: Two models. Journal of Interpersonal Violence, 2, 348-366. https://doi.org/10.1177/088626058700200402 
Finkelhor, D., Shattuck, A., Turner, H. A., \& Hamby, S. L. (2014). The lifetime prevalence of child sexual abuse and sexual assault assessed in late adolescence. Journal of Adolescent Health, 55, 329-333. https://doi.org/10.1016/j.jadohealth.2013.12.026

Fortier, M. A., DiLillo, D., Messman-Moore, T. L., Peugh, J., DeNardi, K. A., \& Gaffey, K. J. (2009). Severity of child sexual abuse and revictimization: The mediating role of coping and trauma symptoms. Psychology of Women Quarterly, 33, 308-320. https://doi.org/ 10.1111/j.1471-6402.2009.01503.x

Franklin, C. A. (2013). Anticipating intimacy or sexual victimization? Danger cue recognition and delayed behavioral responses to a sexually risky scenario. Feminist Criminology, 8, 87-116. https://doi.org/10.1177/1557085112455840

Franz, M. R., DiLillo, D., \& Gervais, S. J. (2016). Sexual objectification and sexual assault: Do self-objectification and sexual assertiveness account for the link? Psychology of Violence, 6, 262-270. https://doi.org/10.1037/vio0000015

Fredrickson, B. L., \& Roberts, T. A. (1997). Objectification theory: Toward understanding women's lived experiences and mental health risks. Psychology of Women Quarterly, 21, 173-206. doi:10.1111/j.1471-6402.1997.tb00108.x

Fredrickson, B. L., Roberts, T.-A., Noll, S. M., Quinn, D. M., \& Twenge, J. M. (1998). That swimsuit becomes you: Sex differences in self-objectification, restrained eating, and math performance. Journal of Personality and Social Psychology, 75, 269-284. https://doi.org/10.1037/0022-3514.75.1.269

Gervais, S. J., Holland, A. M., \& Dodd, M. D. (2013). My eyes are up here: The nature of the objectifying gaze toward women. Sex Roles, 69, 557-570. https://doi.org/10.1007/s11199-013-0316-x 
Gervais, S. J., Vescio, T. K., \& Allen, J. (2011). When what you see is what you get: The consequences of the objectifying gaze for women and men. Psychology of Women Quarterly, 35(1), 5-17. https://doi.org/10.1177/0361684310386121

Gidycz, C. A., McNamara, J. R., \& Edwards, K. M. (2006). Women's risk perception and sexual victimization: A review of the literature. Aggression and Violent Behavior, 11, 441-456. https://doi.org/10.1016/j.avb.2006.01.004

Hart, T. A., Flora, D. B., Palyo, S. A., Fresco, D. M., Holle, C., \& Heimberg, R. G. (2008). Development and examination of the social appearance anxiety scale. Assessment, 15(1), 48-59. https://doi.org/10.1177/1073191107306673

Hebl, M. R., King, E. B., \& Lin, J. (2004). The swimsuit becomes us all: Ethnicity, gender, and vulnerability to self-objectification. Personality and Social Psychology Bulletin, 30, 1322-1331. https://doi.org/10.1177/0146167204264052

Issitt, M. L. (2019). Me Too Sexual Misconduct Movement. Salem Press Encyclopedia.

Jouriles, E. N., Simpson Rowe, L., McDonald, R., Platt, C. G., \& Gomez, G. S. (2011). Assessing women's responses to sexual threat: Validity of a virtual role-play procedure. Behavior Therapy, 42, 475-484. https://doi-org.libproxy.lib.ilstu.edu/10.1016/j.beth.2010.11.005

Koss, M. P., \& Gidycz, C. A. (1985). Sexual experiences survey: Reliability and validity. Journal of Consulting and Clinical Psychology, 53, 422-423. https://doi.org/10.1037/0022-006X.53.3.422

Koss, M. P., \& Oros, C. J. (1982). Sexual experiences survey: A research instrument investigating sexual aggression and victimization. Journal of Consulting and Clinical Psychology, 50, 455-457. https://doi.org/10.1037/0022-006X.50.3.455 
Mallinckrodt, B., Abraham, W. T., Wei, M., \& Russell, D. W. (2006). Advances in testing the statistical significance of mediation effects. Journal of Counseling Psychology, 53, 372378. https://doi.org/10.1037/0022-0167.53.3.372

Marx, B. P. \& Gross, A. M. (1995). Date rape: An analysis of two contextual variables. Behavior Modification, 19, 451-463. https://doi.org/10.1177/01454455950194003

Maxwell, S. E., \& Cole, D. A. (2007). Bias in cross-sectional analyses of longitudinal mediation. Psychological Methods, 12(1), 23-44.

McKinley, N. M., \& Hyde, J. S. (1996). The objectified body consciousness scale development and validation. Psychology of Women Quarterly, 20, 181-215. https://doi.org/10.1111/j.1471-6402.1996.tb00467.x

Mellins, C. A., Walsh, K., Sarvet, A. L., Wall, M., Gilbert, L., Santelli, J. S., Thompson, M., Wilson, P.A., Khan, S., Benson, S., Bah, K., Kaufman, K.A., Reardon, L., \& Hirsch, J. S. (2017). Sexual assault incidents among college undergraduates: Prevalence and factors associated with risk. PLOS ONE, 12(11). https://doi.org/10.1371/journal.pone.0186471

Messman-Moore, T. L., \& Brown, A. L. (2006). Risk perception, rape, and sexual revictimization: A prospective study of college women. Psychology of Women Quarterly, 30, 159-172. https://doi.org/10.1111/j.1471-6402.2006.00279.x

Messman-Moore, T. L., \& Long, P. J. (2003). The role of childhood sexual abuse sequelae in the sexual revictimization of women. Clinical Psychology Review, 23, 537-571. https://doi.org/10.1016/S0272-7358(02)00203-9 
Miles-McLean, H., Liss, M., Erchull, M. J., Robertson, C.M., Hagerman, C., Gnoleba, M. A., \& Papp, L. J. (2015). “Stop looking at me!”: Interpersonal sexual objectification as a source of insidious trauma. Psychology of Women Quarterly, 39, 363-374. https://doi.org/10.1177/0361684314561018

Moradi, B., \& Huang, Y.-P. (2008). Objectification theory and psychology of women: A decade of advances and future directions. Psychology of Women Quarterly, 32, 377-398. https://doi.org/10.1111/j.1471-6402.2008.00452.x

Nurius, P. S., Norris, J., Young, D. S., Graham, T. L., \& Gaylord, J. (2000). Interpreting and defensively responding to threat: Examining appraisals and coping with acquaintance sexual aggression. Violence and Victims, 15(2), 187.

Pereda, N., Guilera, G., Forns, M., \& Gómez-Benito, J. (2009). The prevalence of child sexual abuse in community and student samples: A meta-analysis. Clinical Psychology Review, 29, 328-338. https://doi.org/10.1016/j.cpr.2009.02.007

Reese-Weber, M., \& Smith, D. M. (2011). Outcomes of child sexual abuse as predictors of later sexual victimization. Journal of Interpersonal Violence, 26, 1884-1905. https://doi.org/10.1177/0886260510372935

Rinehart, J.K., \& Yeater, E.A. (2015). Using cognitive theory and methodology to inform the study of sexual victimization. Trauma, Violence \& Abuse, 16 (1), 3-15.

Sherrill, A. M., Bell, K. M., \& Wyngarden, N. (2016). A qualitative examination of situational risk recognition among female victims of physical intimate partner violence. Violence Against Women, 22, 966-985. https://doi.org/10.1177/1077801215616706 
Soler-Baillo, J. M., Marx, B. P., \& Sloan, D. M. (2005). The psychophysiological correlates of risk recognition among victims and non-victims of sexual assault. Behaviour Research and Therapy, 43, 169-181. https://doi.org/10.1016/j.brat.2004.01.004

Steer, A., \& Tiggemann, M. (2008). The role of self-objectification in women's sexual functioning. Journal of Social and Clinical Psychology, 27, 205-225. https://doi.org/10.1521/jscp.2008.27.3.205

Swanston, H. Y., Plunkett, A. M., O’Toole, B. I., Shrimpton, S., Parkinson, P. N., \& Oates, R. K. (2003). Nine years after child sexual abuse. Child Abuse \& Neglect, 27, 967-984. https://doi.org/10.1016/S0145-2134(03)00143-1

Talmon, A., \& Ginzburg, K. (2017). Between childhood maltreatment and shame: The roles of self-objectification and disrupted body boundaries. Psychology of Women Quarterly, 4l(3), 325-337. https://doi.org/10.1177/0361684317702503

Volkert, J., Randjbar, S., Moritz, S., \& Jelinek, L. (2013). Risk recognition and sensation seeking in revictimization and posttraumatic stress disorder. Behavior Modification, 37(1), 39-61. https://doi.org/10.1177/0145445512449647

Walker, H. E., Freud, J. S., Ellis, R. A., Fraine, S. M., \& Wilson, L. C. (2019). The prevalence of sexual revictimization: A meta-analytic review. Trauma, Violence \& Abuse, 20(1), 6780. https://doi.org/10.1177/1524838017692364

Watson, L. B., Matheny, K. B., Gagné, P., Brack, G., \& Ancis, J. R. (2013). A model linking diverse women's child sexual abuse history with sexual risk taking. Psychology of women quarterly, 37(1), 22-37. https://doi.org/10.1177/0361684312454535 


\section{APPENDIX A: MASS EMAIL INFORMED CONSENT}

\section{PLEASE READ THIS PAGE CAREFULLY. YOUR CONSENT IS REQUIRED FOR PARTICIPATION. YOU MUST BE A FRESHMAN WOMAN WHO IS BETWEEN THE AGES OF 18 AND 25 YEARS OF AGE TO PARTICIPATE.}

Description of the Study: This study will ask you to complete a set of questionnaires and read a vignette about two acquaintances interacting with each other.

Nature of Participation: You will spend approximately 30 minutes completing the survey.

Purpose of the Study: The purpose of the study is to examine feelings and behaviors about one's body, dating, and sexual relationships. You can be provided with a complete explanation of the study following the last phase in December. If you are not interested in and don't participate in subsequent phases of this study, please contact Dr. Marla Reese-Weber at mjreese@ilstu.edu or 438-2521 in December.

Possible Risks: When completing the questionnaires, you may come across a question or group of questions that you find unpleasant or upsetting. For instance, a few questions may cause you to think about painful past experiences and/or negative emotional states. You will be asked to provide personal information about yourself, including information pertaining to past sexual experiences and drug use. In the event that you do become upset, simply press "Exit Do Not Finish Survey." If you choose to exit the survey before completion, you will be provided with information about how to contact resources. Please remember you are free to skip questions and continue participating at no penalty.

Possible Benefits: This study will allow participants to contribute to the understanding of cognitive and emotional states among young women as they relate to dating and sexual behaviors. If you desire to be informed about the outcome of this study, you can contact the researcher through the information listed below.

Compensation for your time: You will have the opportunity to enter a raffle for a \$25 Amazon gift card. You will have this opportunity simply by virtue of completing the online survey; you are free to withdraw your participation at any time without penalty. In order to receive compensation, at the end of the survey you will be taken to a separate page to enter your contact information. This information will be kept entirely separate from the survey and your responses. Once the compensation is distributed, we will delete your contact information. The IRS may consider these payments to be taxable compensation. Recipients of a research participant incentive payment may want to consult with their personal tax advisor for advice regarding the participant's situation. Any participant also has the opportunity to participate in the study without accepting the research incentive payment.

Confidentiality: You will create a unique identification number so that your survey responses are anonymous. All data will be kept in secured files, in accord with the standards of the 
University, Federal regulations, and the American Psychological Association. Finally, it is no individual person's responses that interest us; we are studying people in general.

Opportunities to Question: Any technical questions about this research may be directed to Dr. Marla Reese-Weber at mjreese@ilstu.edu or 438-2521. Any questions regarding your rights as a research participant or research-related injuries may be directed to ISU's Office of Research Ethics and Compliance (309) 438-5527.

Opportunities to Withdraw at Will: Your participation is completely voluntary. If you decide now or at any point to withdraw this consent or stop participation, you are free to do so at no penalty to yourself. If you choose to exit the survey before completion, you will be provided with information about how to contact resources. You are also free to skip questions you do not want to answer and continue participating without loss of benefits.

Opportunities to be Informed of Results: In all likelihood, the results will be fully available around the spring of 2020 and will be posted online via ProQuest. In addition, there is a chance that the results from this study will be published in a scientific psychology journal, which would be available in many libraries. In such an article, participants would be identified in general terms such as "freshmen college women." If you have any questions about the research, please contact Dr. Marla Reese-Weber at 438-2521. 


\section{APPENDIX B: SONA INFORMED CONSENT}

\section{PLEASE READ THIS PAGE CAREFULLY. YOUR CONSENT IS REQUIRED FOR PARTICIPATION. YOU MUST BE A FRESHMAN WOMAN WHO IS BETWEEN THE AGES OF 18 AND 25 YEARS OF AGE TO PARTICIPATE.}

Description of the Study: This study will ask you to complete a set of questionnaires and read a vignette about two acquaintances interacting with each other.

Nature of Participation: You will spend approximately 30 minutes completing the survey.

Purpose of the Study: The purpose of the study is to examine feelings and behaviors about one's body, dating, and sexual relationships. You can be provided with a complete explanation of the study following the last phase in December. If you are not interested in and don't participate in subsequent phases of this study, please contact Dr. Marla Reese-Weber at mjreese@ilstu.edu or 438-2521 in December.

Possible Risks: When completing the questionnaires, you may come across a question or group of questions that you find unpleasant or upsetting. For instance, a few questions may cause you to think about painful past experiences and/or negative emotional states. You will be asked to provide personal information about yourself, including information pertaining to past sexual experiences and drug use. In the event that you do become upset, simply press "Exit Do Not Finish Survey." If you choose to exit the survey before completion, you will be provided with information about how to contact resources. Please remember you are free to skip questions and continue participating at no penalty.

Possible Benefits: This study will allow participants to contribute to the understanding of cognitive and emotional states among young women as they relate to dating and sexual behaviors. If you desire to be informed about the outcome of this study, you can contact the researcher through the information listed below.

Compensation for your time: You will have the opportunity to enter a raffle for a \$25 Amazon gift card. You will have this opportunity simply by virtue of completing the online survey; you are free to withdraw your participation at any time without penalty. In order to receive compensation, at the end of the survey you will be taken to a separate page to enter your contact information. This information will be kept entirely separate from the survey and your responses. Once the compensation is distributed, we will delete your contact information. The IRS may consider these payments to be taxable compensation. Recipients of a research participant incentive payment may want to consult with their personal tax advisor for advice regarding the participant's situation. Any participant also has the opportunity to participate in the study without accepting the research incentive payment.

Confidentiality: You will create a unique identification number so that your survey responses are anonymous. All data will be kept in secured files, in accord with the standards of the 
University, Federal regulations, and the American Psychological Association. Finally, it is no individual person's responses that interest us; we are studying people in general.

Opportunities to Question: Any technical questions about this research may be directed to Dr. Marla Reese-Weber at mjreese@ilstu.edu or 438-2521. Any questions regarding your rights as a research participant or research-related injuries may be directed to ISU's Office of Research Ethics and Compliance (309) 438-5527.

Opportunities to Withdraw at Will: Your participation is completely voluntary. If you decide now or at any point to withdraw this consent or stop participation, you are free to do so at no penalty to yourself. If you choose to exit the survey before completion, you will be provided with information about how to contact resources. You are also free to skip questions you do not want to answer and continue participating without loss of benefits.

Opportunities to be Informed of Results: In all likelihood, the results will be fully available around the spring of 2020 and will be posted online via ProQuest. In addition, there is a chance that the results from this study will be published in a scientific psychology journal, which would be available in many libraries. In such an article, participants would be identified in general terms such as "freshmen college women." If you have any questions about the research, please contact Dr. Marla Reese-Weber at 438-2521. 


\section{APPENDIX C: DEBRIEFING STATEMENT}

If after participating in this study you are upset or would like to discuss your interactions with others, you may contact the PATH crisis center for a referral at (309) 827-4005 or 1-800-5707284. You may also contact the Illinois State University Student Counseling Center at (309) 4383655 or http://counseling.illinoisstate.edu/. Please remember that your responses are anonymous, and all data will be kept in secure files. If you have any questions regarding this study, please contact Dr. Marla Reese-Weber at mjreese@ilstu.edu or (309) 438-2521. You may also contact the graduate student conducting this study to satisfy a Master's Thesis in psychology, Michelle Coventry, at mcoven@ilstu.edu. Any questions regarding your rights as a research participant or research-related injuries may be directed to ISU's Office of Research Ethics and Compliance at REC@IllinoisState.edu or (309) 438-5527. 